\title{
ГНОСТИЧЕСКИЕ МОТИВЫ В ТВОРЧЕСТВЕ ВЛАДИМИРА НАБОКОВА (НА ПРИМЕРЕ ПОВЕСТИ СОГЛЯДАТАЙ)
}

\section{GNOSTIC MOTIVES IN THE WORKS OF VLADIMIR NABOKOV (ON THE BASIS OF THE NOVEL THE EYE)}

\author{
NADZIEJA KORTUS
}

\begin{abstract}
AвSTRACт. There are many works that discuss the prose of Vladimir Nabokov in the Gnostic context. The article is an attempt to confront the short novel The Eye of this outstanding writer with the most important determinants of the Gnostic initiation.

Keywords: Gnostic symbols, Vladimir Nabokov, The Eye, initiation path

Nadzieja Kortus, Uniwersytet im. Adama Mickiewicza w Poznaniu, Poznań - Polska, nadia.kortus@gmail.com
\end{abstract}

ORCID ID: 0000-0001-6926-2867

Повесть Владимира Набокова Соглядатай (1930), с которой, по мнению Нины Берберовой, „началась творческая зрелость одного из крупнейших писателей нашего времени" [Мельников 2005: 87], интересна главным образом тем, что в ней впервые появляются те характерные качества набоковской поэтики, в дальнейшем лишь совершенствованные писателем. Среди типичных набоковских приемов, Евгений Вербицкий выделяет, в частности, погружение в сознание выбранного персонажа и жанровый вневизм [Большакова 2013; Вербицкий 2011]. Одной из главных особенностей этого течения является опора на мировую традицию литературы и искусства, где присутствуют элементы мифотворчества, трансцендентности и потусторонности [Большакова 2013]. Главный герой, Смуров-Соглядатай, открывает плеяду набоковских ненадежных nовествователей [Федотова 2007], являющихся alter ego самого Набокова-демиурга. В Соглядатае можно заметить также основные набоковские игровые принципы, основанные на гностических и мистических символах, мотивах, архетипах и мифах. С их помощью Набоков пытается построить авторский инициативный путь в потусторонность, в конце которого перед внимательным читателем, избежавшим все ложные сле- 
ды и ловушки, раскрывается ключ к разгадке правды бытия набоковского художественного космоса [Маликова 2002: 5].

Применяемый здесь символический метод анализа и интерпретации опирается на гностическую символику и соотносится с сильно укоренившимися в набоковедении эзотерическими течениями. При этом стоит учесть, что широко используемое писателем литературное пародирование представляется здесь прежде всего средством оценки некоторых литературно-философских аспектов бурно развивающегося в то время общекультурного течения - Серебряного века. Следуя мнению Александра Млечко, считающего пародию формой выражения интертекстуальной политики, проводимой автором, полагаем, что в основе пародийного начала поэтики Набокова лежит специфика мировидения самого писателя [2000: 21]. По словам Млечко, пародия в Соглядатае выступает не столько как способ организации художественного материала, сколько как форма диалога с традицией:

Ни желание ниспровержения канонов, ни, тем более, тыняновская пародийность не работают в этом случае. Пародия здесь выступает как своеобразная форма памяти - не крушение кумиров, не заполнение пустующих форм новым содержанием, но их творческое обыгрывание, вживление в их казавшуюся мертвой плоть новых смыслов [Млечко 2000: 51-52].

Гностические мотивы в творчестве Владимира Набокова были впервые отмечены Владимиром Александровым [1999] и Сергеем Давыдовым [1995], вслед за ними многие литературоведы интерпретируют набоковское двоемирие как столкновение материальной и духовной действительности. Однако, как подчеркивает Анна Худзиньска-Паркосадзе,

проблема в том, что упрощенная дуалистическая модель не выясняет специфики набоковского хронотопа. Набоков, базируясь на гностической идее иллюзорности и мнимости материального мира, создал добавочный, промежуточный пласт потусторонности, который поместил в пространственно-временной структуре изображенного мира, между миром материальным и истинным, духовным [Худзиньска-Паркосадзе 2016: 175-176].

Вместо дуалистического сопоставления божественного и демонического начал, двоемирие Набокова совмещает внутренний мир героя и мир воображаемой им альтернативной действительности. Таким образом, гностические символы Набоков переводит в плоскость художественного мышления, где „зеркальная поверхность не столько отражает реальность мира физического, сколько воссоздает его мистический подтекст" [Злочевская 2008].

Рассматривая вопрос гностических тем в творчестве Набокова, следует учесть такие сквозные лейтмотивы, как интуиция двоемирия, 
анамнезис, мотив сна, проблема одиночества и отчужденности героя, ощущение пребывания в пространстве материального мира (или его воображенного отражения) как в тюрьме, символика лабиринта, мотив теней (нашедший свое применение в набоковском творчестве в концепции призраков, напоминающей фрейдовскую сферу подсознания ид [Злочевская 2008]), идея демиурга, парадигма инициации, идеал гения, проблема избранности, идея спасения через гностическое знание, идея смерти через обретение свободы и, наконец, идея спасения через настоящую любовь, объектом которой является женщина, отожествляемая с идеалом Вечной Женственности.

Соглядатай - это первое произведение Набокова, написанное от первого лица. Следовательно, в повести заметно значительное сходство между стилем автора и главного героя, Смурова [Баллард 2008; Федотова 2009; Вербицкий 2011; Полева 2012: 133-138; Сверчкова 2013: 177-179]. Писатель словно выдвигает их на первый план, благодаря чему цепочка Смуров- рассказчик-Набоков прочно держится, неоднократно приводя неолытного, поддающегося изысканной набоковской игре читателя, к однозначному прочтению авторского кредо. Лишь при учете автобиографического подхода ясным становится фонетическая игра английского перевода заглавия повести (Тhe Еуе понимается как я/глаз), поскольку именно сквозь мысли и решения главного героя-повествователя Набоков впервые в своем творчестве заявляет, что на самом деле он - автор-демиург, т.е. создатель миров и правил, в них действующих:

...послушно моей воли выросла вокруг меня прозрачная больничная палата... [Набоков: 2];

...мое воображение при жизни было так мощно, так пружинисто, что теперь хватало его надолго [Набоков: 2];

...по желанию моему я ускоряю или, напротив, довожу до смешной медлительности движение всех этих людей, группирую их по-разному, делаю из них разные узоры, освещаю их то снизу, то сбоку... [Набоков: 6];

Так, все их бытие было для меня только экраном [Набоков: 6] ${ }^{1}$.

Структура главного героя, Смурова, основана на принципе зеркального отражения. Несмотря на амбивалентность его изображения (личность Смурова, распадающаяся по ходу действия на несколько совершенно не похожих друг на друга ипостасей, окончательно так и не получает цельного образа), читатель постепенно идентифицируется со Смуровым, теряя критическое и объективное восприятие его характера

${ }^{1}$ Ссылки на интернет-издание повести Соглядатай приводятся в тексте с указанием в квадратных скобках фамилии и номера главы [Набоков: 1-6]. 
и действий. Таким же зеркалом для Набокова является читатель - интерпретатор его художественного мира: „Ведь меня же нет, - есть только тысячи зеркал, которые меня отражают. С каждым новым знакомством растет население призраков, похожих на меня" [Набоков: 6]. Благодаря этому приему, согласно логике многих набоковских произведений, место Смурова-Соглядатая занимает любой читатель, ищущий вместе с рассказчиком обещанную истину, вместо которой обнаруживает финальное авторское обвинение: „...вы все... жестокие, самодовольные...” [Набоков: 6]. Таким образом, сам Набоков ставит себя в оппозицию к читателю, признаваясь, что на самом деле, независимо от мнения окружающих, он - „неуязвим" и „счастлив" [Набоков: 6] - творец.

Принцип зеркального отражения распространяется также и на других героев произведения, благодаря чему личность Смурова словно множится в их глазах [Федотова 2009], ср: „...все те люди, которых я встречал - не живые существа, а только случайные зеркала для Смурова..." [Набоков: 6]. Следовательно, целое пространство повести приобретает значение мира теней, живущих лишь в воображении главного героя. Причем, как мир, так и обитающие в нем тени являются воспроизведениями наблюдающего за ними их первообраза - заглавного соглядатая. В контексте вышесказанного интересным становится замечание Федотовой о том, что

...сама литературная деятельность нарратора дает терапевтический эффект психоаналитического сеанса, а содержание повести - это содержание беседы пациента с психоаналитиком, правда, с той особенностью, что они соединены в одной личности. Финал повести ставит успешность этого психоаналитического сеанса под вопрос: я нарратора остается, как и в начале повести, наедине с многочисленными тенями и масками других, травматическое ядро продолжает оставаться внутри него самого, и поэтому Другой воспринимается как недостаточный, блокированный, несостоятельный [Федотова 2009].

Путь раскрытия личности Смурова и столкновение героя с абстрактным понятием Другого на самом деле является попыткой преодолеть страх перед определением и оцениванием себя другими. Единственной защитой неуверенного в себе человека становится творчество - сотворение себя и других. С помощью целого ряда приемов, среди которых первую скрипку играет заглавной зазеркальный соглядатай, автор создает собственное, фиктивное alter ego демиурга, обитающее в альтернативном мире и являющееся богом судьбы своих героев.

Зеркальный мотив в Соглядатае не только организует мир героев, но также играет структурообразующую роль двоемирия. Во-первых, образ зеркала разделяет повесть на три части: первой границей является смерть героя (Смуров стреляет себе в сердце после того, как увидел свое 
зеркальное отражение), а следующей границей - его внезапное соединение с зеркальным соглядатаем у выхода из цветочного магазина. Во-вторых, зеркало открывает путь к тайне потусторонности, поскольку после смерти главного героя происходит дезинтеграция его сознания на эго-Смурова и наблюдающего за ним соглядатая-тени. Уже с потусторонней перспективы герой делится с читателем своей рефлексией:

...после наступления смерти человеческая мысль продолжает жить по инерции... земная мысль, освобожденная от тела, продолжает двигаться в кругу, где все по-прежнему связано, где все обладает сравнительным смыслом, и что потусторонняя мука грешника именно и состоит в том, что живучая его мысль не может успокоиться, пока не разберется в сложных последствиях его земных опрометчивых поступков [Набоков: 2].

Убивая прежнего Смурова, он попадает в мир теней, где за зеркальными отражениями остальных героев-теней наблюдает его личная тень - соглядатай-рассказчик: „Странное воспоминание... Даже теперь, когда многое изменилось, - даже теперь я слегка замираю, вызывая из памяти, как опасного преступника из камеры, то странное воспоминание" [Набоков: 1]. С момента смерти Смурова, как пространство и время, так и его сознание разделяются на два пласта - до смерти и после смерти. Поскольку сам соглядатай предстает в виде подсознания Смурова, представленный мир соглядатая носит черты субъективного воображения Смурова. Цель соглядатая - создать „бессмертный образ Смурова” [Набоков: 5], поэтому он и пытается произвести определенное впечатление на окружающих.

Подобно тому как в Приглашении на казнь, так и в Соглядатае волшебное зеркало вводит героя в его индивидуальную потустороннюю зону и является средством постижения сокровенной тайны личности [Злочевская 2008]. Как Цинциннат оказался не в материальном мире, а в иллюзорном, зеркальном пространстве, отражающем материальный мир, так и тень Смурова после мнимой смерти своего властелина, продолжает наблюдать за ним в мире теней; и так же, как в набоковском представлении о духовном прозрении Цинцинната, именно призрак-тень Смурова торжествует, преодолевая мнимый враждебный мир.

Следующим гностическим мета-мотивом, организующим композицию и хронотоп повести, является мотив сна. Во-первых, он выступает в контексте сбывшейся мечты героя: „И только во сне, обливаясь слезами, я ее наконец обнимал, но она всегда вырывалась..." [Набоков: 5]. Во-вторых, ощущение погружения в сон сопутствует смуровскому воображению о его возлюбленной, Вани: „Ваню я отметил сразу, и сразу почувствовал сердцебиение, как во сне, когда добыча мечты тут у тебя в комнате" [Набоков: 2]. 
Но гораздо важнее то, что онирические черты свойственны целому потустороннему пространству, куда герой попадает после смерти прежнего Смурова. Момент перехода в сферу потусторонности происходит в спальне. Согласно Екатерине Полевой, старушка, заботящаяся о спальне, выполняет функцию проводника в инобытие [Полева 2012]. В эпизоде самоубийства, до совершения данного акта, в спальне суетится старушка-хозяйка: стелет постель, застегивает штору. После ее ухода герой смотрит в зеркало, тушит свет и стреляет себе в сердце. Совместно с символом сердца, выступает также мотив воды, отсылающий к бессознательному. Более того, вода является символом физического, психического и духовного очищения и возрождения, а также соотносится с женским началом (кувшин, который старушка наполняет водой, после выстрела рука Смурова погружается в пол „как в бездонную воду”) [Oesterreicher-Mollwo 2009: 334-336]. Мотивы смерти и сна продолжают сосуществовать также и во второй части произведения, когда герой просыпается и после встречи с Вайнштоком решает, что этот разговор „оказался началом для него новой жизни" [Набоков: 2]. Кстати, первым знакомым лицом, которое в потусторонности увидел Смуров, оказалась та же старушка-немка. При этом, сон воспринимается Смуровым не как отдохновение, прекращение активности сознания, а наоборот, как жестокий жизненный опыт:

Я же, всегда обнаженный, всегда зрячий, даже во сне не переставал наблюдать за собой, ничего в своем бытии не понимая, шалея от мысли, что не могу забыться, и завидуя всем тем простым людям - чиновникам, революционерам, лавочникам, - которые уверенно и сосредоточенно делают свое маленькое дело. [...] И я был так одинок [Набоков: 1].

Здесь, кроме соотнесения предсмертной жизни Смурова с гностическим сном-забвением, имеем дело с моментом, предшествующим диссоциации героя, объясняемой тем, что он не простой человек, а избранник, который осознает свое страдание и видит его источник в собственной исключительности. Герой знает и ощущает больше, чем обыкновенные люди. Смуров является образцом гностического избранника - яркой, талантливой личностью, тем самым обреченной на одиночество:

Признаюсь, в те первые вечера он на меня произвел довольно приятное впечатление. [...] Он держался прекрасно, улыбался спокойно, немного грустной улыбкой, медлившей у него на губах. Говорил он мало, но все высказываемое им было умно и уместно, а редкие шутки его, слишком изящные, чтобы вызвать бурный смех, открывали в разговоре потайную дверцу, впуская неожиданную свежесть. Казалось, что он не мог сразу же не понравиться Ване, именно этой благородной, загадочной скромностью, бледностью лба и узостью рук... Кое-что, 
- например, слово „благодарствуйте”, произносимое полностью с сохранением букета согласных, - должно было непременно открыть чуткому наблюдателю, что Смуров принадлежит к лучшему петербургскому обществу [Набоков: 2].

Следует обратить внимание и на тот факт, что избранничество Смурова подтверждается лишь субъективным мнением его тени - соглядатая-рассказчика (т.е. его самого, о чем читатель догадывается не сразу). Глядя перед смертью в зеркало, он оказывается не способным соотнести свое отражение маленького человека с собственным сверхчеловеческим внутренним ощущением. Отчаянное эгоистическое отношение к жизни как к легкому безответственному сну является тем многим, что изменилось для Смурова после перехода в потусторонность. Кроме того, в финале повести он готов верить в иллюзию мнимого посмертного опыта - свободу воли, обусловленную демиургической силой сознания. В итоге герой отказывается от этического переживания своей пошлости ради эстетического вкуса и таланта:

И пускай сам по себе я пошловат, подловат, пускай никто не знает, не ценит того замечательного, что есть во мне, - моей фантазии, моей эрудиции, моего литературного дара... Я счастлив тем, что могу глядеть на себя, ибо всякий человек занятен, - право же занятен! Мир, как ни старайся, не может меня оскорбить, я неуязвим [Набоков: 6].

Чувство отчуждения и одиночества - наиболее характерная черта многих героев набоковских произведений. При этом, как замечает Худзиньска-Паркосадзе, „концепт одиночества избранника развертывается в двух противоположных направлениях: аллегорической пародии на внешний мистический опыт, и истинное внутреннее мистическое переживание" [2016: 173]. В данном произведении, в пародийном ключе представлен потусторонний опыт другого героя повести Вайнштока, антипода Смурова, и его любовницы, а настоящее внутреннее мистическое переживание свойственно лишь Смурову.

Однако смерти героя не предшествует никакое откровение, а только отчаяние по поводу несоответствия его жалкого внешнего облика с возвышенным образом гения в его сознании. Как избранничество Цинцината в Приглашении на казнь вытекает из его способа восприятия окружающего мира (он с рождения и по природе отличался от других), так и Смуров не только видит и ощущает больше, чем другие, но также чувствует себя чуждым в мире и не понимает законов его существования, ср.: „ничего в своем бытии не понимая” [Набоков: 1]. Однако вопреки собственному предназначению Смуров не выполняет никакой миссии по отношению к окружающему миру, не является ни спасителем, ни проповедником, не борется за правду. Проблема в том, что герою недо- 
ступна настоящая любовь - необходимое условие мистического переживания и положительно завершенной инициации [Яковлев 2001: 555-559]. Смуров признается, что ему не к кому было писать предсмертное письмо, так как он „никого не любил” [Набоков: 1].

Гностический концепт материального мира, символически представленного в виде лабиринта, реализуется в Соглядатае сквозь поиски нового Смурова и систему зеркальных отражений героев. Являясь аспектами его личной тени, они не дают ему покоя. Отчаянные попытки создать новый облик настоящего Смурова кончаются поражением, и герой вынужден бежать от окружающих его враждебных призраков. Спасением оказывается его субъективное, творческое сознание. Проблема в том, что оно не соответствует в идейном плане внутренней свободе и чистой духовной силе человека-избранника, т.е. того, кто обрел тайну бытия. Гностическая идея освобождения от этого мира благодаря сверхъестественному знанию переосмысляется Набоковым как побег из этого мира теней в потусторонний мир воображения. Несмотря на то, что пространство воображения иерархически выше в категории пространственно-временных пластов духовного измерения, оно не тождественно чисто духовному пространству. В „набоковском рае” истинная любовь невозможна, так как ее вытесняет эгоистическое само-восхищение творческого, демиургического „я": „И какое мне дело, что она выходит за другого? У меня с нею были по ночам душераздирающие свидания, и ее муж никогда не узнает этих моих снов о ней. Вот высшее достижение любви" [Набоков: 6].

Концепт отчуждения и побег из этого мира, неразрывно связаны в творчестве Набокова с мотивом погони за призраком идеальной женщины [Бугаева 2010; Kortus 2015a: 153-163; Kortus 2015b: 197-210]. Симптоматично, что герой принимает решение о самоубийстве сразу после позорного провала своего романа с Матильдой (ее муж избивает любовника). Импульсом к воссоединению и возврату в реальный мир оказывается отказ со стороны его возлюбленной Варвары (Вани).

В результате этого разговора, сознание Смурова заново интегрируется со своей „соглядатайской” тенью. Смуров, выходя из цветочного магазина, видит свое отражение в зеркале и в этот же момент происходит воссоединение тени-повествователя с эго-Смуровым: „...взявшись за дверную скобку, я увидел, как сбоку в зеркале поспешило ко мне мое отражение, молодой человек в котелке, с букетом. Отражение со мною слилось, я вышел на улицу" [Набоков: 6].

Однако это воссоединение не является достижением высшего душевного состояния. Герой-рассказчик сопротивляется собственному восстановлению и возвращению в реальность. Он ищет доказательств своей 
смерти и когда находит в стене комнаты отметину, оставленную пулей, успокаивается, заново попадая в сомнамбулическое состояние: „...мир сразу приобретал опять успокоительную незначительность, я снова был силен, ничто не могло смутить меня, я готов был вызвать взмахом воображения самую страшную тень из моей прошлой жизни" [Набоков: 6]. Таким образом, предыдущее несознательное состояние не преодолевается настоящим гностическим просвещением адепта, который после смерти должен был воскреснуть в условиях нового, высшего, гармоничного существования.

Не без значения остается также и тот факт, что именно мнение Вани насчет его самого интересует героя наиболее: „Что скрывать: все те люди, которых я встречал, - не живые существа, а только случайные зеркала для Смурова, но одно существо среди них - самое важное для меня, самое ясное зеркало - все еще отказывалось выдать мне смуровское отражение" [Набоков: 5]. Оказывается, что среди всех остальных героев-теней только Ваня видит его настоящий облик - хорошего, умного, доброго человека. Тем не менее, именно оценка, данная Ваней, усугубляет его отчаяние. Однажды, во время своих мучительных любовных переживаний, герой вдруг осознает, что он бежит не за Ваней, а именно за ее призраком:

То, что мне нужно было от Вани, я все равно никогда бы не мог взять себе в вечное свое пользование и обладание, как нельзя обладать окраской облака или запахом цветка. И только когда я наконец понял, что все равно мое желание неутолимо и что Ваня всецело создана мной, я успокоился, привыкнув к своему волнению и отыскав в нем всю ту сладость, которую вообще может человек взять от любви [Набоков: 5].

Ваня, „эта девушка - клад” [Набоков: 4], играет роль чистой идеи, живущей лишь в сознании героя. Она, в некоторой степени, восходит к образу гностической Софии [Jonas: 76]. Причем об этом идеале женственности Смуров думает брезгливо и небрежно: „что мне было до того, глупа ли она или умна" [Набоков: 5]. Именно провал этой сакральной идеи в сознании героя заново сталкивает его с той реальностью, избежать которую он пытался еще с попытки суицида в начале повести.

Оказывается, что смерть, воспринимаемая как побег, не приводит героя к обретению свободы, поскольку бегство само по себе - это еще не спасение [Versluis 1995: 33]. Порочный круг жизни и смерти не превращается в спираль творческого самосовершенствования. Становясь mвориом своего загробного существования, Смуров подчиняет силе своего воображения лишь личные воспоминания, касающиеся собственного эго, в то время как преградой к обретению истинного духовного облика стоит личная тень героя - его собственный соглядатай. 


\section{Библиография}

Александров В. Е. 1999. Набоков и потусторонность: метафизика, этика, эстетика, Санкт-Перербург: Алетейя.

Баллард А. 2008. Столкновение творческих сил $b$ „Соглядатае” Набокова, электронный ресурс: http://ifi.rsuh.ru/vestnik_2008_1_19.html (доступ: 1.08.2017).

Большакова С. 2013. Вневизм: история, теория, библиография, электронный ресурс: http://bolshakova.su/vnevizm-istoriya-teoriya-bibliografiya.html (доступ: 1.08.2017).

Бугаева Л. 2010. В поисках „Ultima Thule”: Набоков, [в:] Л. Бугаева, Литература u „rite de passage", Санкт-Петербург: Петрополис.

Вербицкий Е. 2011. Повесть „Соглядатай” В. Набокова: предтеча вневизма в его творчестве, электронный ресурс: http://vnevizm.liveforums.ru/viewtopic.php?id=369 (доступ: 1.08.2017).

Злочевская А. 2008. Парадоксы зазеркалья в романах Г. Гессе, В. Набокова и М. Булгакоba, „Вопросы литературы”, № 2, электронный ресурс: http://magazines.russ.ru/ voplit/2008/2/zl9-pr.html (доступ: 1.08.2017).

Маликова М. 2002. Набоков: авто-био-графия, Санкт-Петербург: Академический проект.

Мельников Н. 2005. „Детектив, воспринятый всерьез...”. Философские „антидетекmивы” В.В. Набокова, „Вопросы литературы”, № 4, электронный ресурс: http:// www.philol.msu.ru/ tlit/texts/nm28.htm (доступ: 1.08.2017).

Млечко А. В. 2000. Игра, метатекст, трикстер: пародия $b$ "русских" романах В. В. Набокова, Волгоград: Издательство Вогоградского государственного университета.

Набоков В. В. 1989. Другие берега, Москва: Книжная палата.

Набоков В. В. 2012. Соглядатай, Москва: Азбука-классика, электронный ресурс: http:/ / www.lib.ru/NABOKOW/thespy.txt (доступ: 1.08.2017).

Полева Е. 2012. Семантика сна $b$ почести В. Набокова „Согладатай”, „Вестник Томского государственного педагогического университета", № 9, электронный ресурс: https://cyberleninka.ru/article/n/semantika-sna-v-povesti-v-nabokova-soglyadatay (доступ: 1.08.2017).

Сверчкова А. 2013. „Своеобразие и эволюция стиля В. Набокова в рассказах сборников «Соглядатая» и «Весна в Фиальте»", автореферат диссертации на соискание ученой степени кандидата филологических наук (на правах рукописи), Екатерибург.

Федотова Е. 2007. „Соглядатай” В. Набокова: между „я" и „другим”, „Rossica Petropolitana Juniora", вып. 1, электронный ресурс: http://mir.spbu.ru/index.php?option= com_k2\&view=item\&id=771: rpj-07 (доступ: 1.08.2017).

Худзиньска-Паркосадзе А. 2016. Одиночество „избранных". Попытка освещения проблемы на материале романа Владимира Набокова „Приглачение на казнь”, [в:] К. Arciszewska, L. Kalita, U. Potocka-Sigłowy (ред.), Samotność - aspekty, konteksty, wymiary, т. 2, Gdańsk: Wydawnictwo Uniwersytetu Gdańskiego.

Яковлев М. В. 2001. Мистическое, [в:] А. Н. Николюкин (ред.), Литературная энциклопедия терминов и понятий, Москва: НПК Интелвак.

Davydov S. 1995. Nabokov and Pushkin, [в:] V. Aleksandrov (ред.), The Garland Companion to Vladimir Nabokov, New York: Garland.

Jonas H. 1994. Religia gnozy, przeł. M. Klimowicz, Kraków: Platan. 
Kortus N. 2015а. Путешествие в потусторонность - мифические контексты в рассказе Владимира Набокова „Ultima Thule”, „Kultury Wschodniosłowiańskie - Oblicza i Dia$\log ^{\prime \prime}$, № 5 .

Kortus N. 2015b. Тень демиурга или несостоявшийся "rite de passage" Владимира Набокова (на примере незавершенного романа „Solus Rex"), [в:] K. Rutecka, K. Arciszewska (ред.), Ciemność i światto, т. 6, Gdańsk: Wydawnictwo Uniwersytetu Gdańskiego.

Oesterreicher-Mollwo M. 2009. Herder. Leksykon symboli, przeł. J. Prokopiuk, Warszawa: $\mathrm{tCHu}$.

Versluis A. 1995. Gnosis and Literature, Saint Paul: Grail. 
